\title{
Stability analysis of primary emulsion using a new emulsifying agent gum odina
}

\author{
Amalesh Samanta, Durbadal Ojha, Biswajit Mukherjee* \\ Department of Pharmaceutical Technology, Jadavpur University, Kolkata, India; Corresponding Author: biswajit55@yahoo.com
}

Received 1 February 2010; revised 10 March 2010; accepted 18 March 2010.

\begin{abstract}
Gum odina and various parts of the plant Odina wodier are traditionally used in Indian folk medicine. Here an effort was made to investigate the efficacy of gum odina as new pharmaceutical excipients, in particular, as an emulsifying agent. Primary emulsion was prepared using wet gum method taking oil: water: gum (4:2:1) with gum acacia powder as an emulsifying agent. This was used as a standard control formulation. In case of experimental emulsions the primary emulsion was prepared by same wet gum technique taking oil: water: gum (4:2:0.5) (gum content was just a half of gum acacia) by using gum odina powder as an emulsifier. The gum odina as emulsifying agent provided a stable emulsion at a very low concentration as compared to the amount required for other conventional natural emulsifying agents. Stability studies of the emulsion were made as per the ICH guideline to study thermal stability, photosensitivity, $\mathrm{pH}$ related stability and stability in presence of oxygen. The emulsion type was identified by staining techniques (dye test by using Sudan III) as o/w type preparation without creaming or cracking even after long storage for 24 months at $25^{\circ} \mathrm{C}$. It was found that the emulsion containing gum odina produced more stable emulsion at a much lower amount as compared to the emulsion stabilized by gum acacia.
\end{abstract}

Keywords: Emulsifying Agent, Gum Odina, Odina wodier

\section{INTRODUCTION}

Use of various gums as pharmaceutical excipients is nothing new. As a stabilizer and thickening agent, use of natural gum has been found in the literature about five thousand years back [1]. Some natural or induced-exuda- tion of normally neutral or slightly acidic complex of polysaccharides or partially acetylated polysaccharide or heterogeneous polysaccharide are obtained as a mixture with calcium, potassium and magnesium salts [2-3]. As a natural defense mechanism to prevent infection or dehydration many trees and shrubs are known to produce an aqueous thick exudation when the plants bark is injured [4]. Eventually the solution dries up in contact with sunlight and air and a hard transparent brown-tint glass like mass is formed. This solid exudation is commonly known as natural gum [4-5]. Some of the gums used frequently now-a-days as pharmaceutical excipients and /or in food industry are gum acacia, gum tragacanth, gum Karaya etc. Gum acacia is mainly used in the confectionary industry. Traditionally it is used in candies to provide the appropriate texture so that they do not adhere to the teeth. Gum acacia is used in chewing gum as a coating agent [6-7] and is also used as emulsifier in soft drink industries [8]. Pharmaceutically gum acacia is still used as a suspending agent, emulsifier, adhesive and tablet binding agent [9-11]. In cosmetic industry it is used as a stabilizer in lotions and protective creams, where it increases viscosity, imparts spreading properties and maintains a protective coating [4].

Gum tragacanth is used in ice creams to provide texture to the product [12] and acts as a thickener and provides texture for chewy sweets such as lozenges [13]. Gum tragacanth is widely used in pharmaceutical industry as an effective suspending agent. Gum tragacanth is used as a stabilizer in dermatological creams and lotions and it also provides a protective coating [14-15]. Suspending properties are used in jellies and tooth paste giving spreadibility and a shiny creamy appearance [16-17].

Gum Karaya is well-studied for stabilizing low $\mathrm{pH}$ emulsion such as sauces [18]. Due to the water binding capacity of Gum karaya it extends the shelf-life of baked goods. It is widely used as stabilizer, thickener, texturiser and emulsifier in foods. Powdered Gum karaya is widely applied on dental plates as an adhesive [19]. It is used as a bulk laxative, and also used as an adhesive in leak- 
proof sealing rings for post surgical drainage pouches or osotomy bags and in skin lotions [20-22].

In recent past we described the use of gum odina (Figure 1(a)) as an excellent substitute of starch paste as a tablet binder [23]. Odina wodier, Roxb. family Anacardiaceae is a large tall tree (Figure 1(b)) found in deciduous forest in India, Myanmar, Srilanka, China, Malaysia, Cambodia and Philippine Islands [24]. It is popularly known as Kashmala, Odimaram, Jiol in local language and in English it is called Rhus olina [25]. Various parts of this plant have been found to be used as medicines in Ayurveda. The leaves have been reported to use in Elephantiasis of the legs [25]. Juice of green branches is used as an emetic in case of coma or insensibility produced by narcotic. The dried and powdered bark is found to use as tooth powder by poor villagers [24]. The bark extract has been reported to be useful in vaginal trouble, curing ulcer, heart diseases etc. [26].

In the presence study we investigated and compared the emulsifying property of the gum odina (obtained from Odina wodier, Roxb. Family Anacardiaceae) with respect to that of a well-known natural gum emulsifier (gum acacia) and the stability aspects of emulsion prepared with the gum.

\subsection{Materials and Methods}

Chemicals procured for preparing emulsion were cod liver oil (E. Merck Ltd, Mumbai, India) and acacia powder (E. Merck Ltd, Mumbai, India). All other chemicals were of analytical grade and used as received if not otherwise mentioned.

\subsection{Collection of Gum Odina}

Gum was collected from the tree Odina wodier, Roxb., family Anacardiaceae during Autumn in the month of August from the Mandal Ghat of Jalpaiguri, West Bengal, India. The gum was the natural exudates on the bark of the tree. It was collected in a dry condition. After collection of the gum, the entire work was carried out in the Department of Pharmaceutical Technology, Jadavpur University.

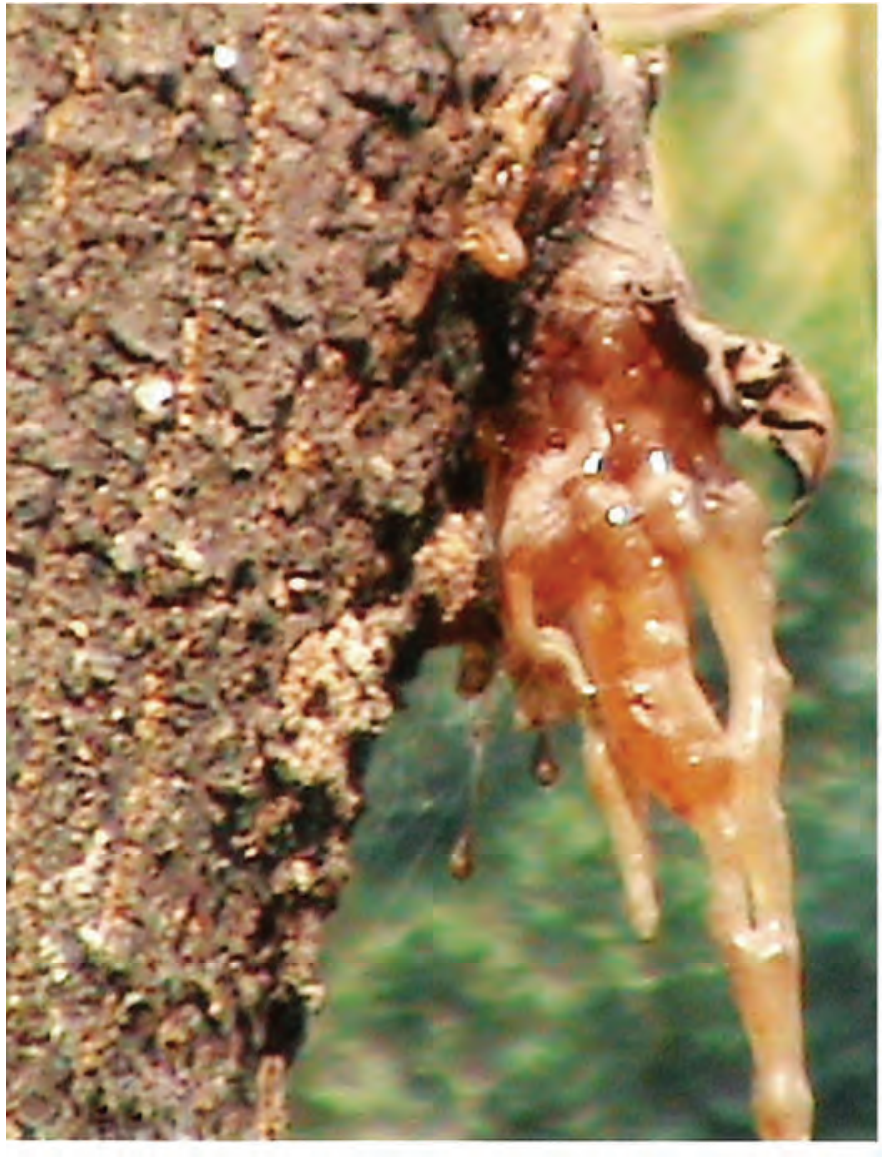

(a)

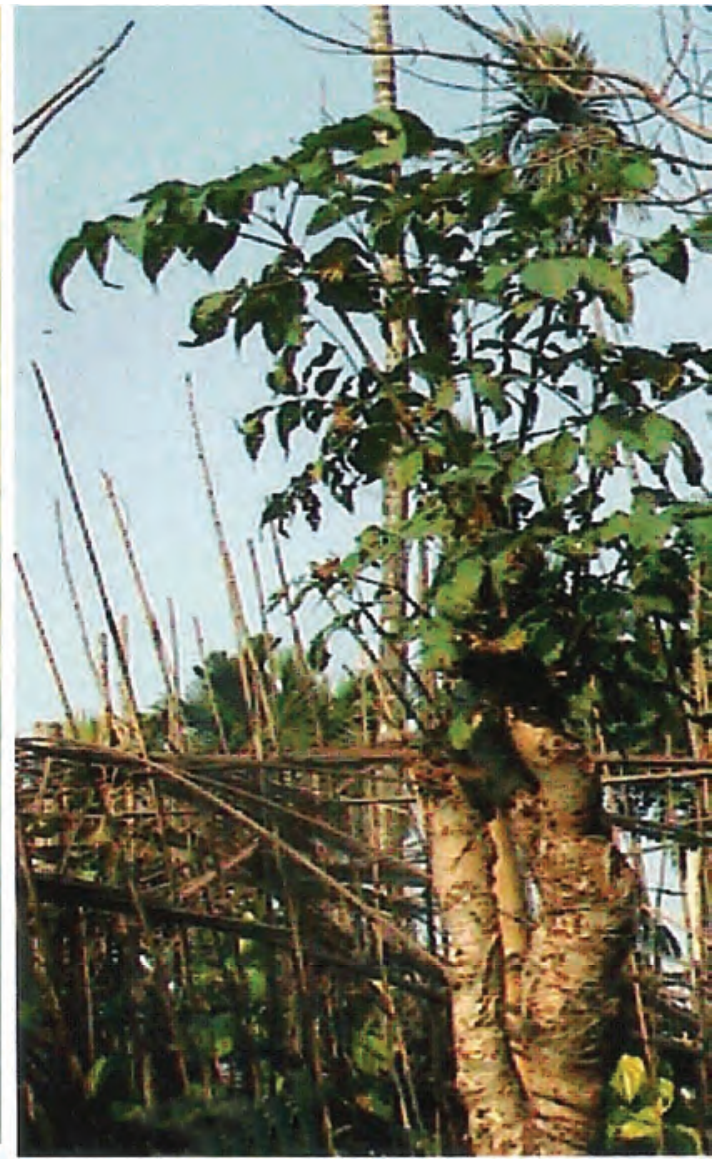

(b)

Figure 1. (a) Transparent reddish brown needle shape gum liberating from the bark of the plant; (b) Tree of Odina wodier, Roxb., family Anacardiaceae. 


\section{FORMULATION DEVELOPMENT}

\subsection{Formula for Preparation of Primary Emulsion}

Formulation was developed by conventional "wet gum" technique [27]. Formula for primary emulsion was prepared using "wet gum" method taking oil: water: gum (4:2:1) with gum acacia powder as an emulsifying agent. This was used as standard control formulation. In case of experimental emulsions (test sample) the primary emulsion was prepared by the same "wet gum" technique taking oil: water: gum (4:2:0.5) (gum content is just a half of gum acacia) by using gum odina powder as an emulsifier (Table 1).

\subsection{Procedure for the Preparation of Emulsion}

3.75 gm of experimental gum (gum odina) was taken in a mortar and thick mucilage was prepared by taking $15 \mathrm{ml}$ of water using a pestle. Then to it, required volume $(30 \mathrm{ml})$ of cod liver oil was added drop-wise with constant and uniform clockwise trituration to make a primary emulsion [27]. Final volume was adjusted to $90 \mathrm{ml}$ with water (Table 1).

\subsection{Stability Study of Emulsion}

\subsubsection{FTIR Study}

IR grade $\mathrm{KBr}$ with a drop of respective emulsion was compressed into pellets by applying 5.5 metric tons of pressure in a hydraulic press and scanned over a wave number of $4000 \mathrm{~cm}^{-1}-400 \mathrm{~cm}^{-1}$ in a FTIR spectrophotometer 8400S Shimadzu.

\subsubsection{Thermal Stability}

Prepared emulsions were kept (test and control) at different temperatures namely $20^{\circ} \mathrm{C}, 40^{\circ} \mathrm{C}$ and $60^{\circ} \mathrm{C}$ for one month by following ICH guideline [28]. Samples were taken out and FTIR spectroscopy was done.

\subsubsection{Stability at variable $\mathrm{pH}$}

Initial $\mathrm{pH}$ of the prepared emulsion was 4.75. To determine the stability at different $\mathrm{pH}$ values, the emulsion were adjusted at different $\mathrm{pH}$ conditions namely 2, 7.4 and 10 by using $0.1(\mathrm{~N}) \mathrm{HCl}$ and $0.1(\mathrm{~N}) \mathrm{NaOH}$ as applicable and kept for one month both for test and control. Then the FTIR spectroscopic studies of the sample were done.

Table 1. Composition of primary emulsion.

\begin{tabular}{ll}
\hline \multicolumn{1}{c}{ Control } & \multicolumn{1}{c}{ Experimental } \\
\hline Cod-liver oil-30 ml. & Cod-liver oil-30 ml. \\
Water q.s $-90 \mathrm{ml}$ & Water q.s $-90 \mathrm{ml}$ \\
Acacia powder-7.5 g & Gum odina powder - $3.75 \mathrm{~g}$ \\
\hline
\end{tabular}

\subsubsection{Photo-Stability}

To determine the photo-stability, the formulations (the test and control samples) were exposed to 40 watt (2216.16 CP), 60 watt (3656.66 CP) and 100 watt (5540.4 CP) using electric bulbs. That was adjusted 6 inches above the formulations kept in transparent glass bottle capped tightly in a closed chamber for one month. Following this study FTIR spectra were determined and compared with the samples not exposed to light (i.e. kept in a dark place at $4^{\circ} \mathrm{C}$ ) [29].

\subsubsection{Oxygenation of Emulsion and FTIR Study}

To analyze the susceptibility of the prepared emulsion containing gum to oxidation, $30 \mathrm{ml}$ of emulsion in a glass bottle of $50 \mathrm{ml}$ capacity was continuously exposed to a stream of $\mathrm{O}_{2}(5 \mathrm{~L} / \mathrm{min})$ for $1 \mathrm{~h}$ and the samples were capped tightly and kept for 15 days before being analyzed by studying their FTIR spectra.

$30 \mathrm{ml}$ of emulsion in a glass bottle of $50 \mathrm{ml}$ capacity was continuously exposed to inert environment by using a stream of $\mathrm{N}_{2}(5 \mathrm{~L} / \mathrm{min})$ (considered as control against oxidation) for $1 \mathrm{~h}$ and the samples were kept for 15 days before being analyzed by studying their FTIR spectra.

\section{CHARACTERIZATION OF EMULSION}

\subsection{Viscosity of Emulsion}

Dynamic viscosity of the prepared emulsion was measured using Brook-field rotational viscometer TV-10 (Toki Sangyo Co. Pvt.Ltd, Tokyo, Japan) rotated at $60 \mathrm{rpm}$ for one minute. The length and diameter of the cylinders were 10.5 $\mathrm{cm}$ and $3 \mathrm{~cm}$ respectively. Length and diameter of the spindles were $6.4 \mathrm{~cm}$ and $1.8 \mathrm{~cm}$ respectively.

\subsection{Test for Identifying Emulsion Type (Dye Test)}

Several tests are available for distinguishing between o/ $\mathrm{w}$ and w/o type emulsions. They include tests of miscibility, dye test, electrical conductivity measurements etc. We adopted for dye test here.

\subsection{Dye Test}

Prepared emulsion $(10 \mathrm{ml})$ was triturated with Sudan III (0.05 g) and a drop of it was placed on a microscope slide, covered with a cover-slip and examined under a microscope.

\subsection{Cracking of Emulsion}

This involves coalescence of the dispersed globules and separation of the disperse phase as a separate layer. Redispersion cannot be achieved by shaking and the ad- 
vantages of emulsification are lost and accurate dosage is impossible. Simple visual observation (of the stored samples about 24 months) was the means to detect cracking.

\subsection{Creaming of Emulsion}

Creaming may be defined as the formation of a layer of relatively concentrated emulsion and this conditions favours breakdown of the interface and consequent coalescence of the oil globules and therefore, the emulsion may eventually crack. By shaking, creaming may disappear in many cases. Simple visual observation technique (of the stored sample about 24 months) was the method adopted here to determine creaming.

\section{RESULTS}

The various parts of Odina wodier have been used in Ayurveda and traditional Indian folk medicine (24). We have recently reported the gum of this plant as a tablet binder, effective at a much lower concentration as compared to the other available natural binders and further, the gum is devoid of toxicity [23]. In the present study we have mainly focused on the utility of the gum as an emulsifying agent of natural origin and the stability aspects of emulsions prepared using this emulsifying agent.

The dynamic viscosity of prepared emulsion (4:2:0.5) was measured using Bookfield type rotational viscometer TV-10, rotated at $60 \mathrm{rpm}$ for one minute and the viscosity was 14 centipoises.

Several tests are available for the differentiation of types of primary emulsions i.e. o/w and w/o type emulsions. These tests are miscibility with water, Dye test and Electrical conductivity measurements etc. [27]. Dye test is a very common test to determine the types of emulsion. The dispersed globules were appeared 'red' due to oil soluble dye Sudan III and the continuous phase was 'colourless' (Figure 2) in the present study.

Stability of emulsion was analyzed by comparing the FTIR spectra of the freshly prepared experimental emulsion (Figure 3) and the stored (24 months) experimental emulsion (Figure 4). Physical interactions were detected between wave number $700 \mathrm{~cm}^{-1}$ and $600 \mathrm{~cm}^{-1}$ upon prolonged storage as compared to the freshly prepared samples.

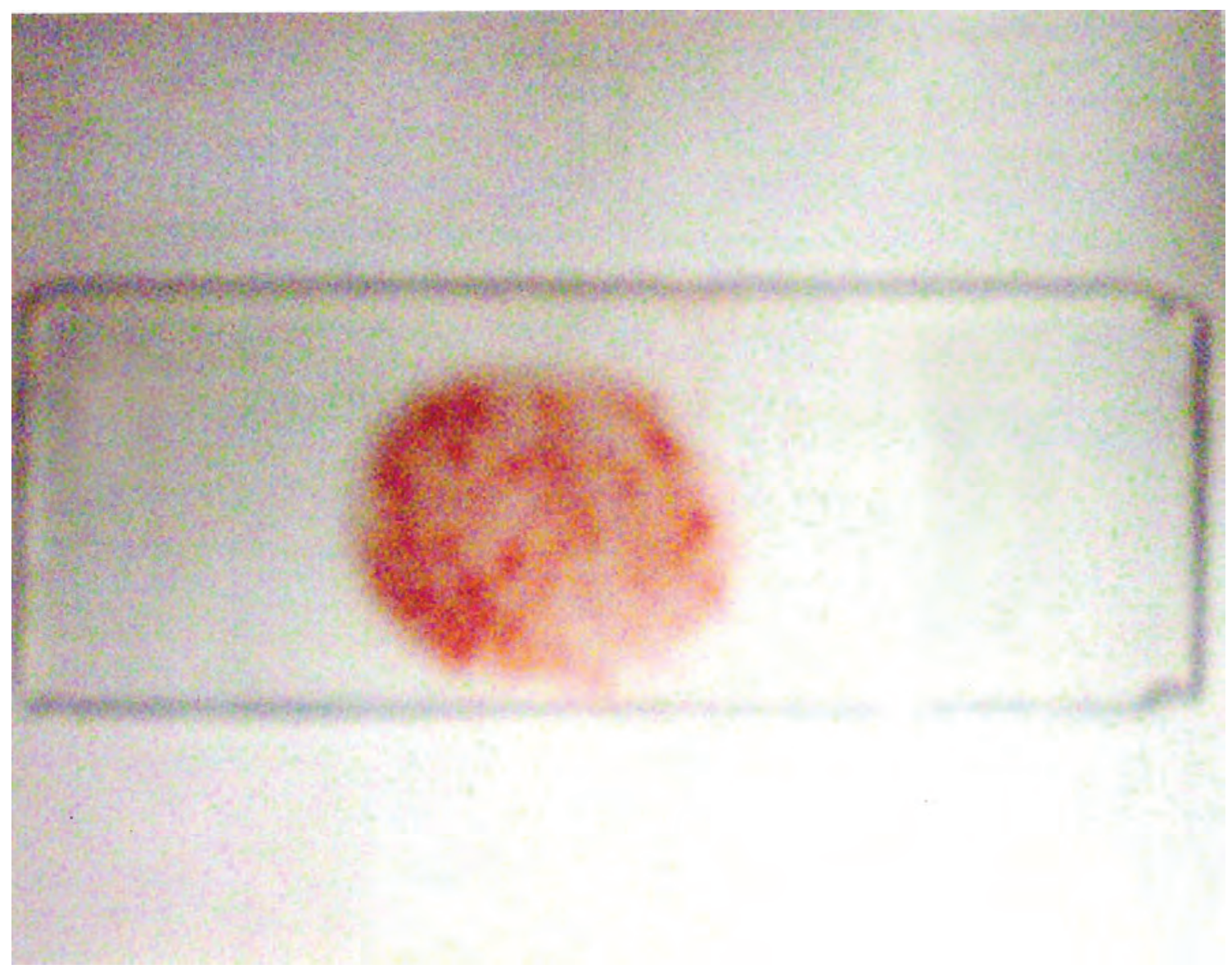

Figure 2. Determination of o/w type of emulsion i.e. dispersed oil globules appeared 'red' and continuous phase 'colourless'. 


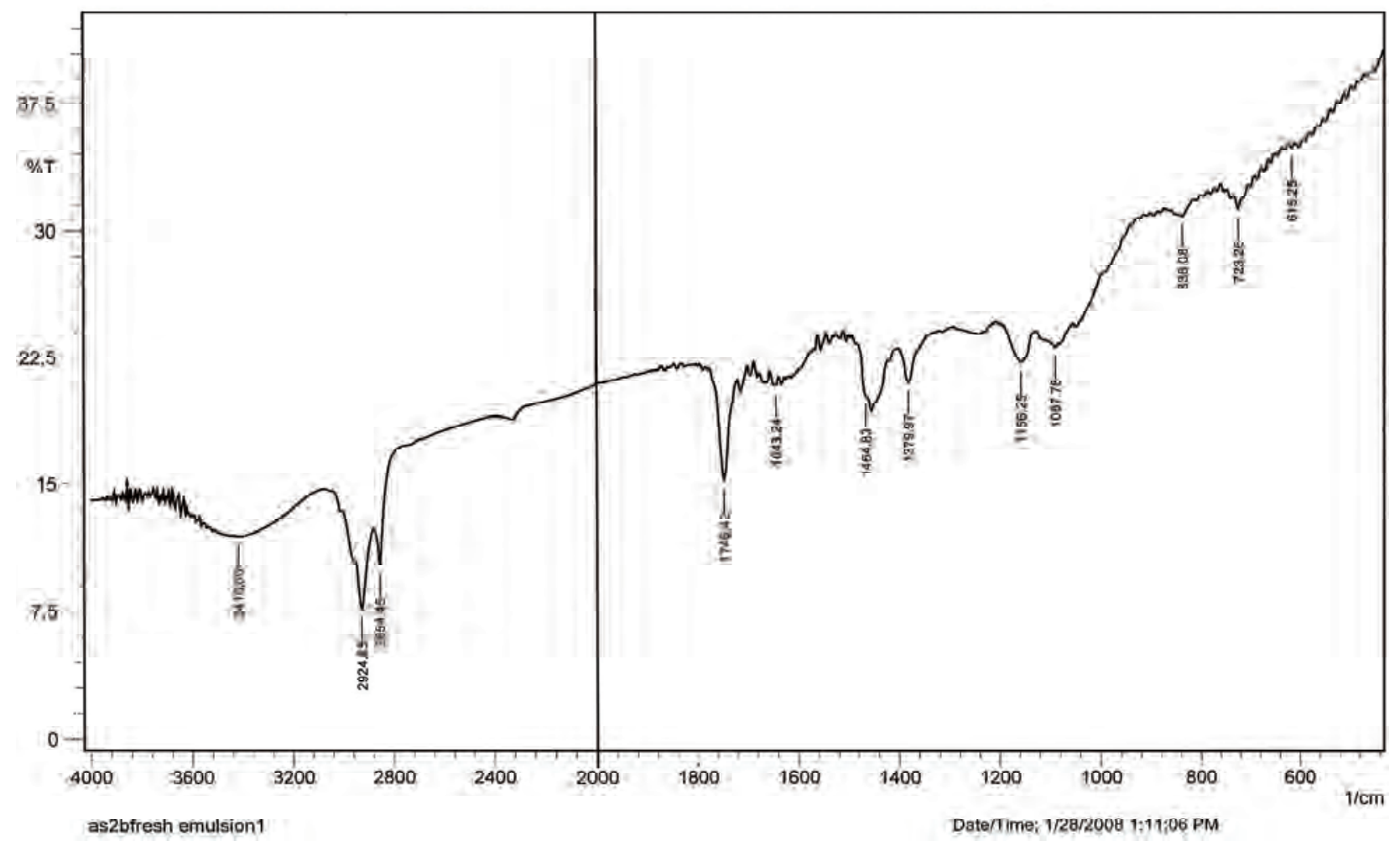

Figure 3. FTIR spectra of freshly prepared experimental emulsion.

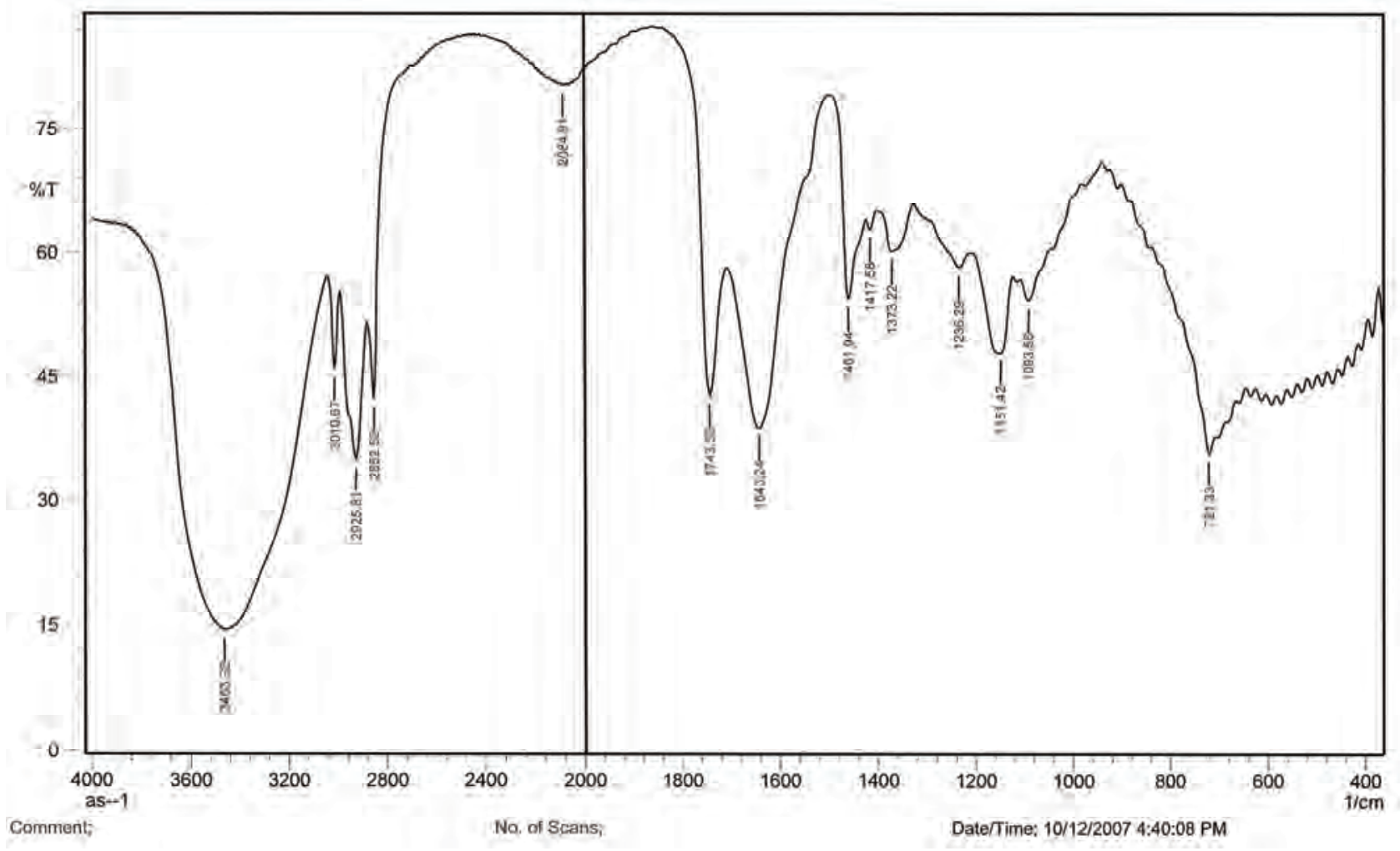

Figure 4. FTIR spectra of stored (24months) experimental emulsion kept at room temperature. 
Thermal stability of emulsion was analyzed by studying the FTIR spectra of the emulsions stored at $20^{\circ} \mathrm{C}$, $40^{\circ} \mathrm{C}$ and $60^{\circ} \mathrm{C}$ for 30 days (Figures 5-7). Interactions were detected in the wave numbers between $2700 \mathrm{~cm}^{-1}$ and $720 \mathrm{~cm}^{-1}$ for the samples stored at $40^{\circ} \mathrm{C}$ and $20^{\circ} \mathrm{C}$; and wave number at $3461 \mathrm{~cm}^{-1}, 2099 \mathrm{~cm}^{-1}, 1646 \mathrm{~cm}^{-1}$, $718 \mathrm{~cm}^{-1}$ in case of the sample stored at $60^{\circ} \mathrm{C}$ (Figures 7-9). The types of interaction have been discussed in details in discussion section.

The impacts of variable $\mathrm{pH}$ on emulsion stability were detected by changing the $\mathrm{pH}$ of emulsion at 2, 7.4 and 10; these were stored for 30days at room temperature. This was followed by the FTIR spectroscopy and the data indicate that there were variations in wave numbers in the range between $3500 \mathrm{~cm}^{-1}$ and $2600 \mathrm{~cm}^{-1}$ and also at $1744 \mathrm{~cm}^{-1}$ at $\mathrm{pH} 7.4$ (Figures 8-10).

For studying the photostability, the emulsion was exposed to 60 Watt (3656.66 CP) for 30 days and the FTIR spectra were compared with the experimental emulsion stored in the dark for the same period. There were physical interactions detected in the range of wave numbers between $3600 \mathrm{~cm}^{-1}$ and $2800 \mathrm{~cm}^{-1}$ (Figure 3 and Figure 11) and also in the range between $2400 \mathrm{~cm}^{-1}$ and 1700 $\mathrm{cm}^{-1}$. Otherwise no predominant variations in the FTIR spectra were detected when photo-exposed samples were compared.

To know the stability of emulsion exposed to oxidation, samples were exposed either to oxygen or nitrogen (which was used as control) as specified earlier. No interactions were detected upon oxygenation except some minor peak variation at the wave numbers $2665 \mathrm{~cm}^{-1}$, $3457 \mathrm{~cm}^{-1}, 1437 \mathrm{~cm}^{-1}, 1148 \mathrm{~cm}^{-1}$ (Figures 12 and 13). However, all the characteristic peaks of the gum were present.

Creaming and cracking of the stored emulsions (24 months) were also visually observed but no such phenomenons were detected.

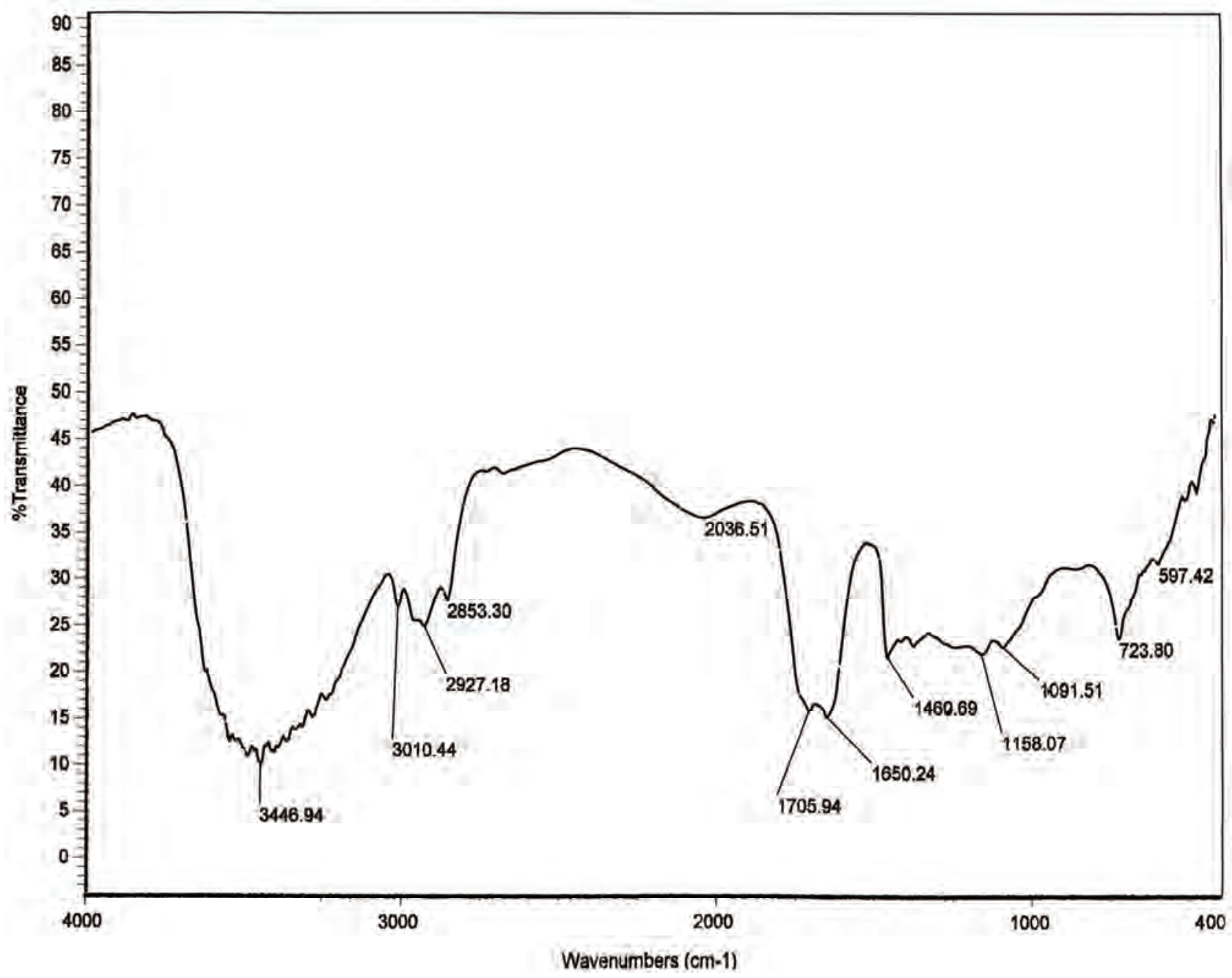

Figure 5. FTIR spectra of thermal stability of emulsion at $20^{\circ} \mathrm{C}$. 


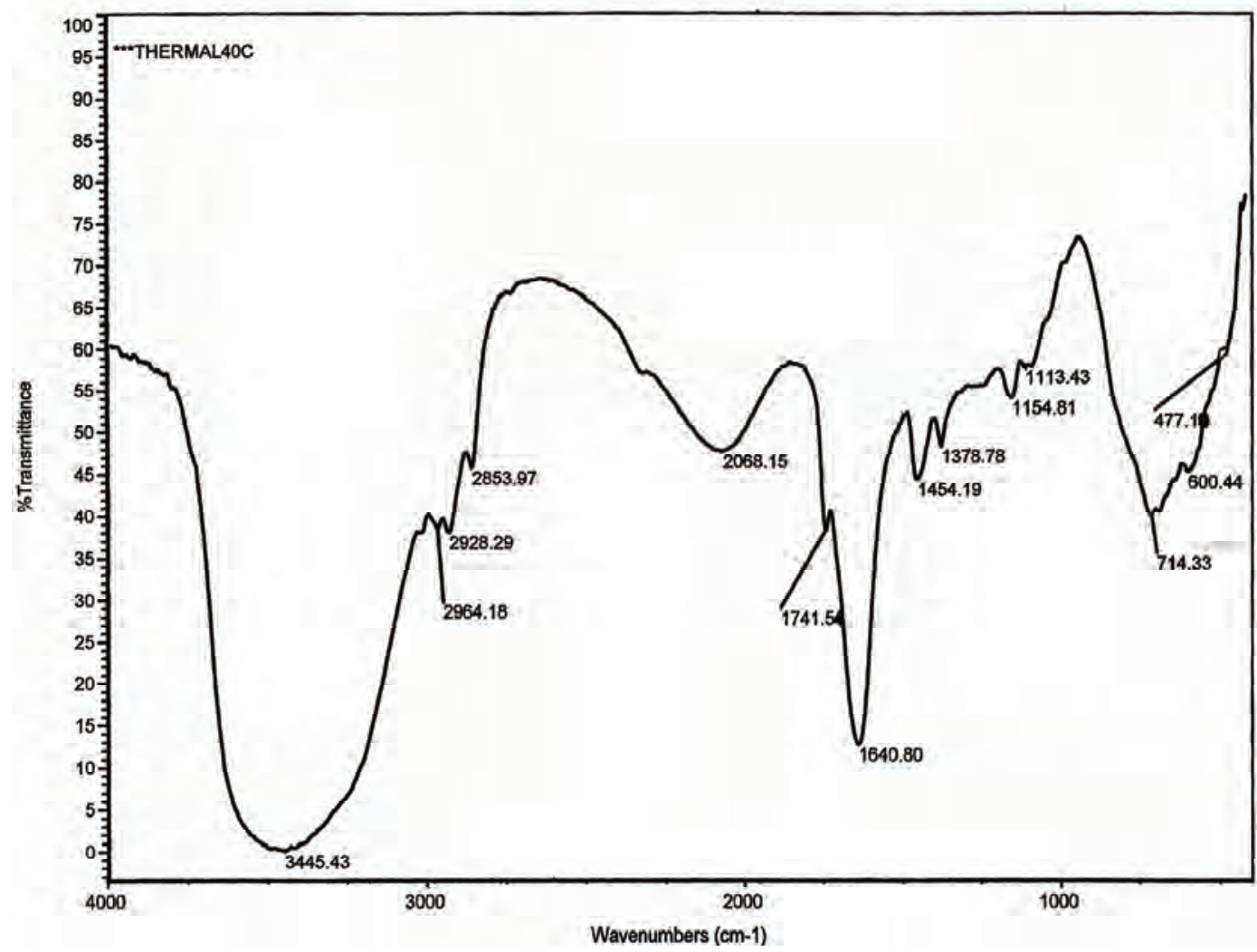

Figure 6. FTIR spectra of thermal stability of emulsion at $40^{\circ} \mathrm{C}$.

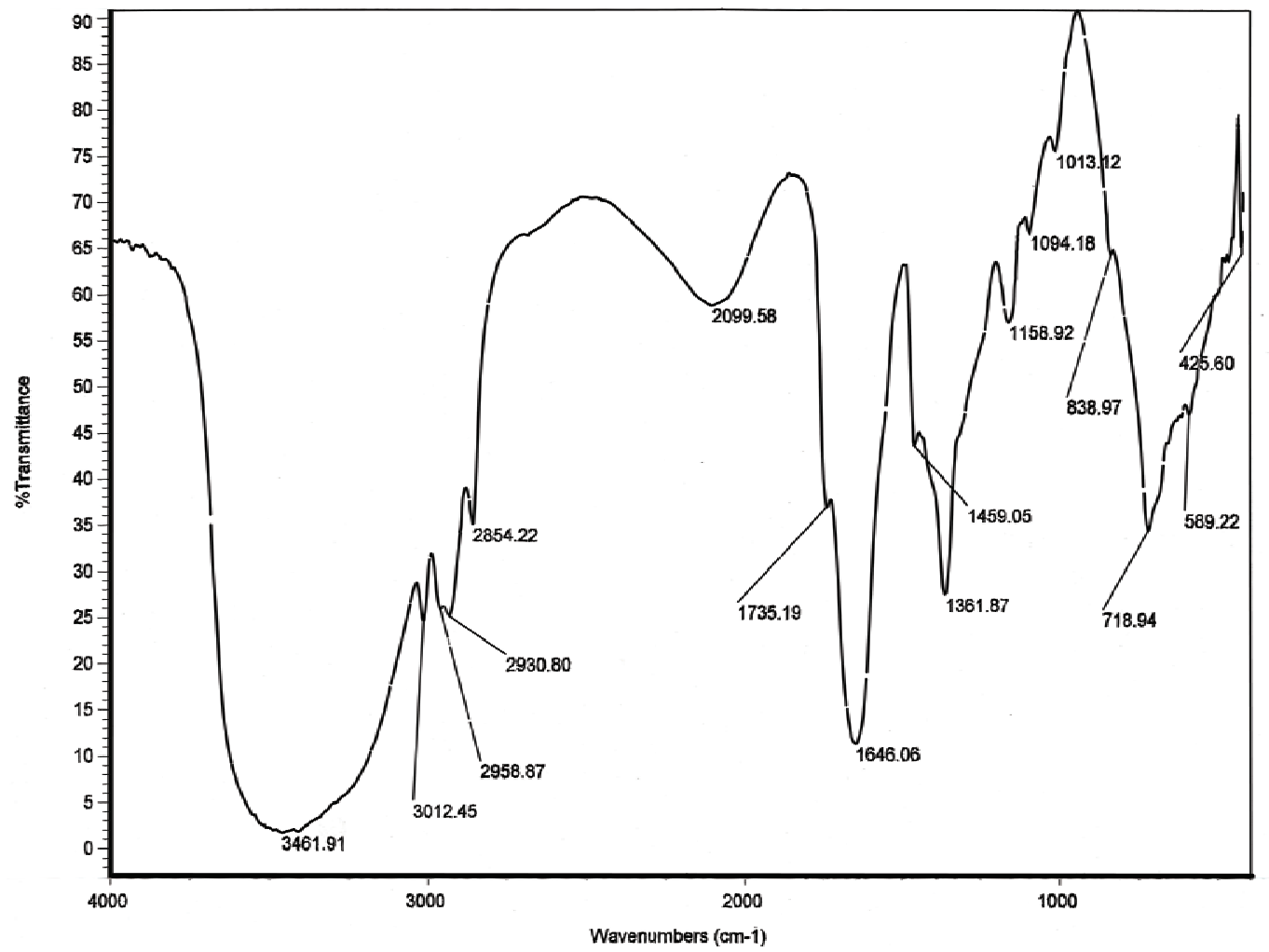

Figure 7. FTIR spectra of thermal stability of emulsion at $60^{\circ} \mathrm{C}$. 


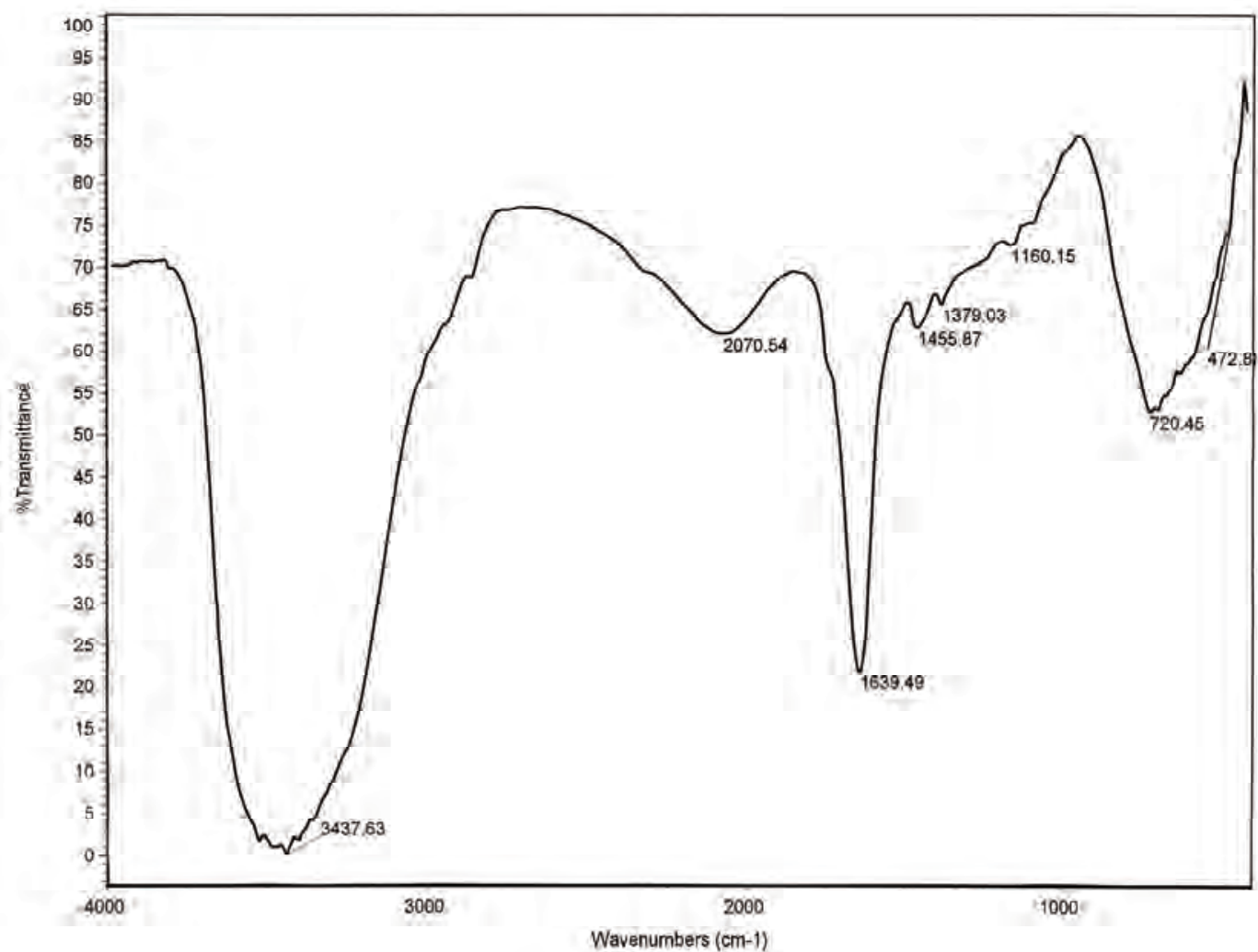

Figure 8. FTIR spectra of emulsion with $\mathrm{pH} 2$.

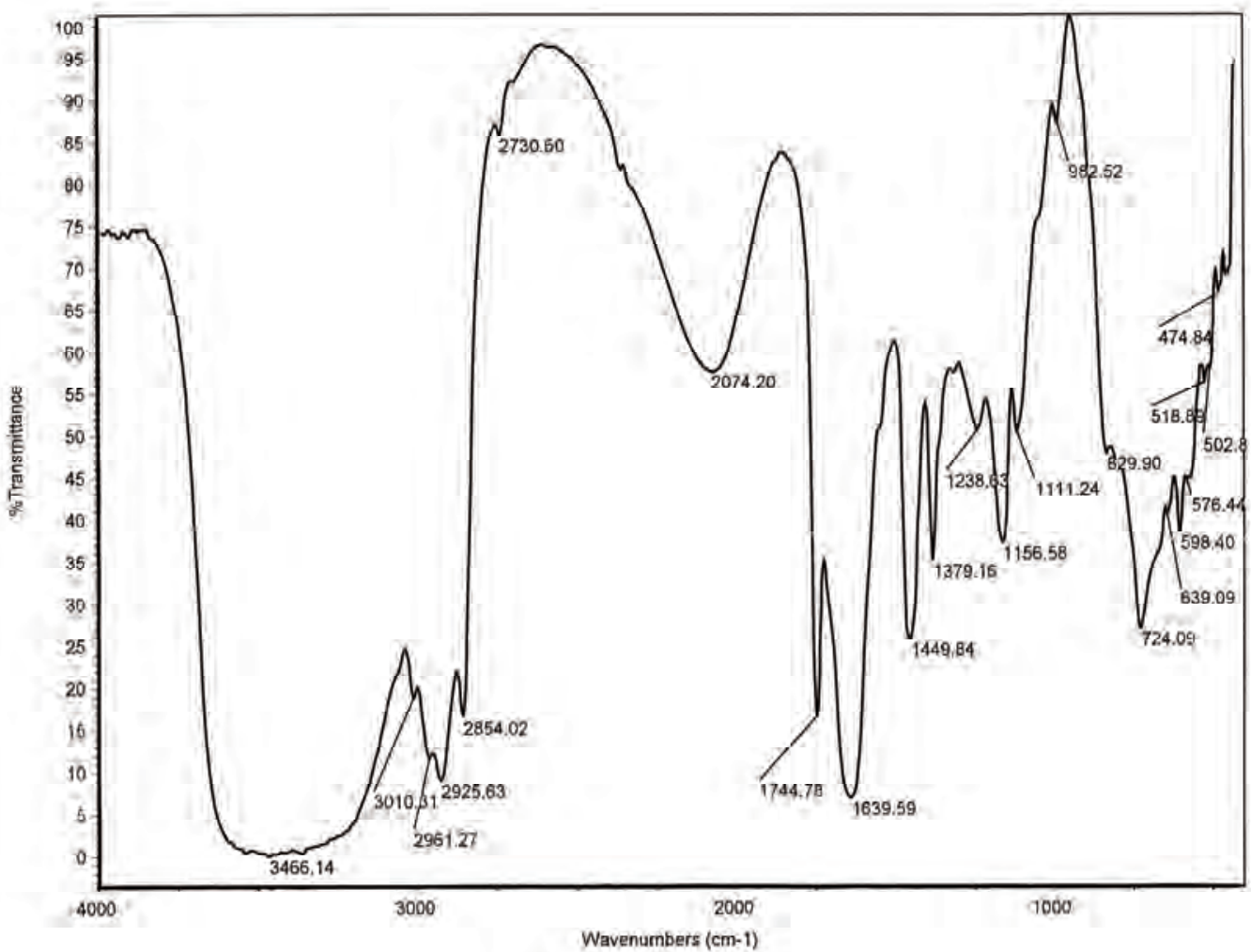

Figure 9. FTIR spectra of emulsion with pH 7.4. 


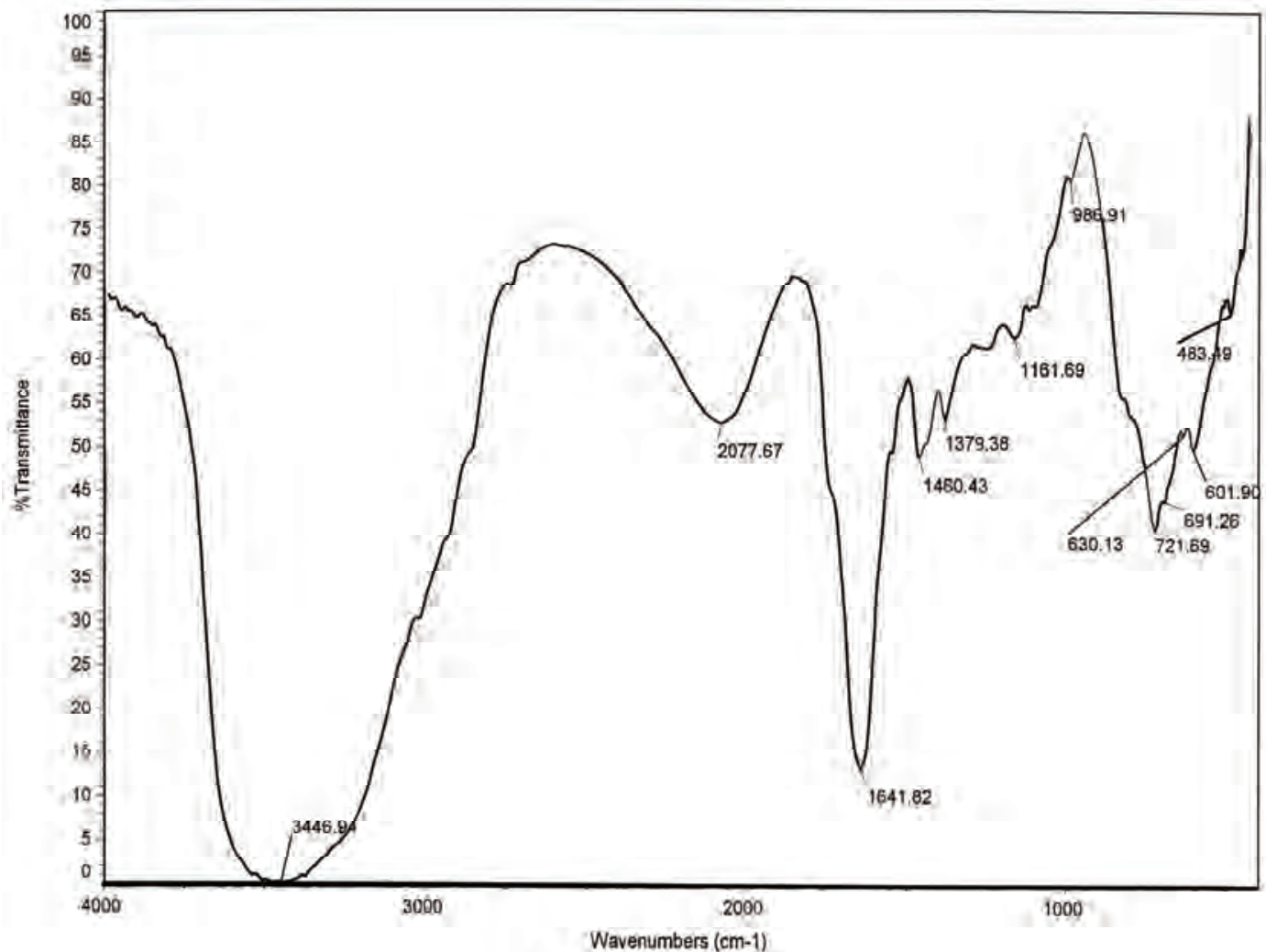

Figure 10. FTIR spectra of emulsion with $\mathrm{pH} 10$.

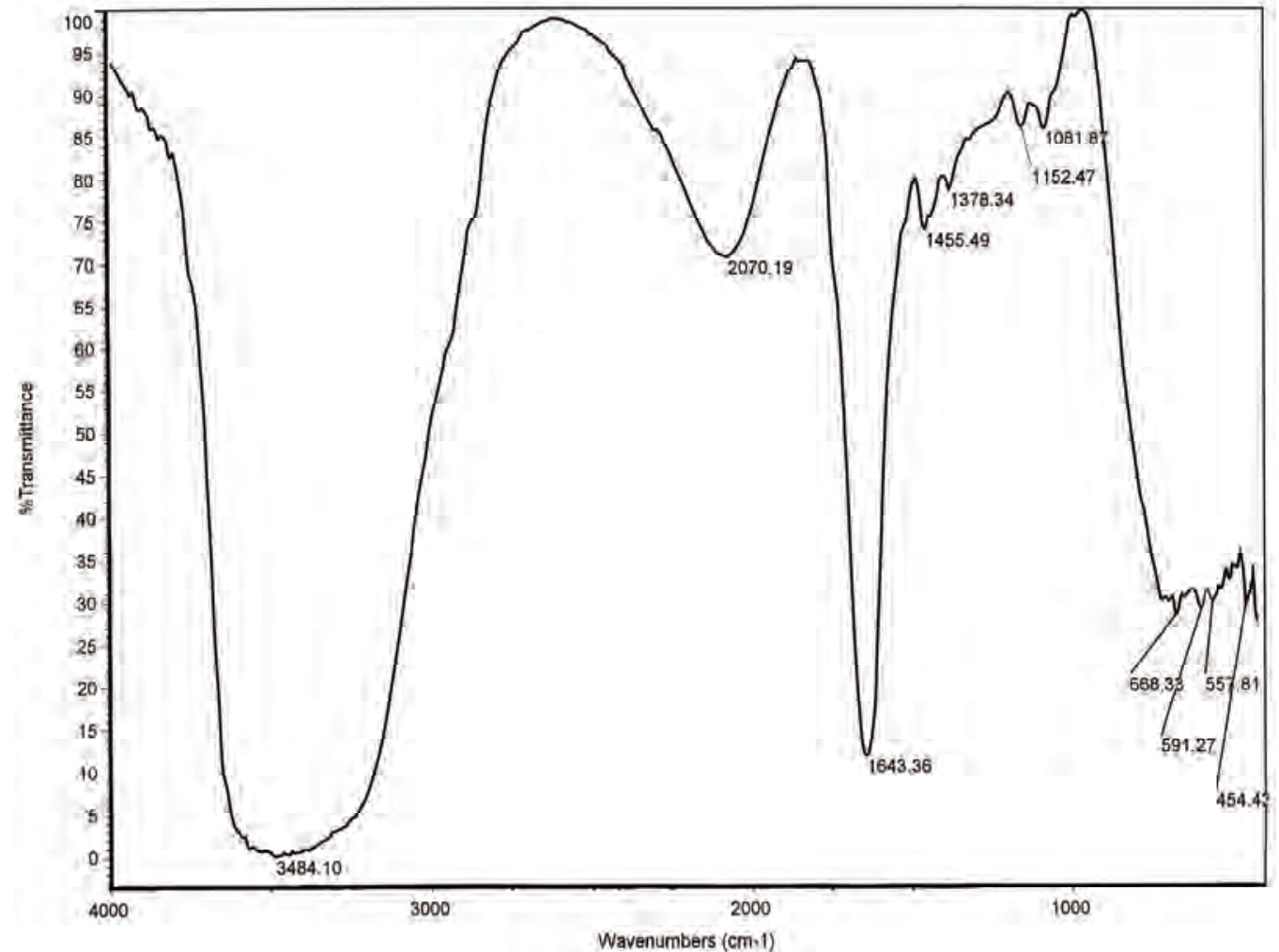

Figure 11. FTIR spectra of photo stability of emulsion at 60 Watt. (3656.66 CP). 


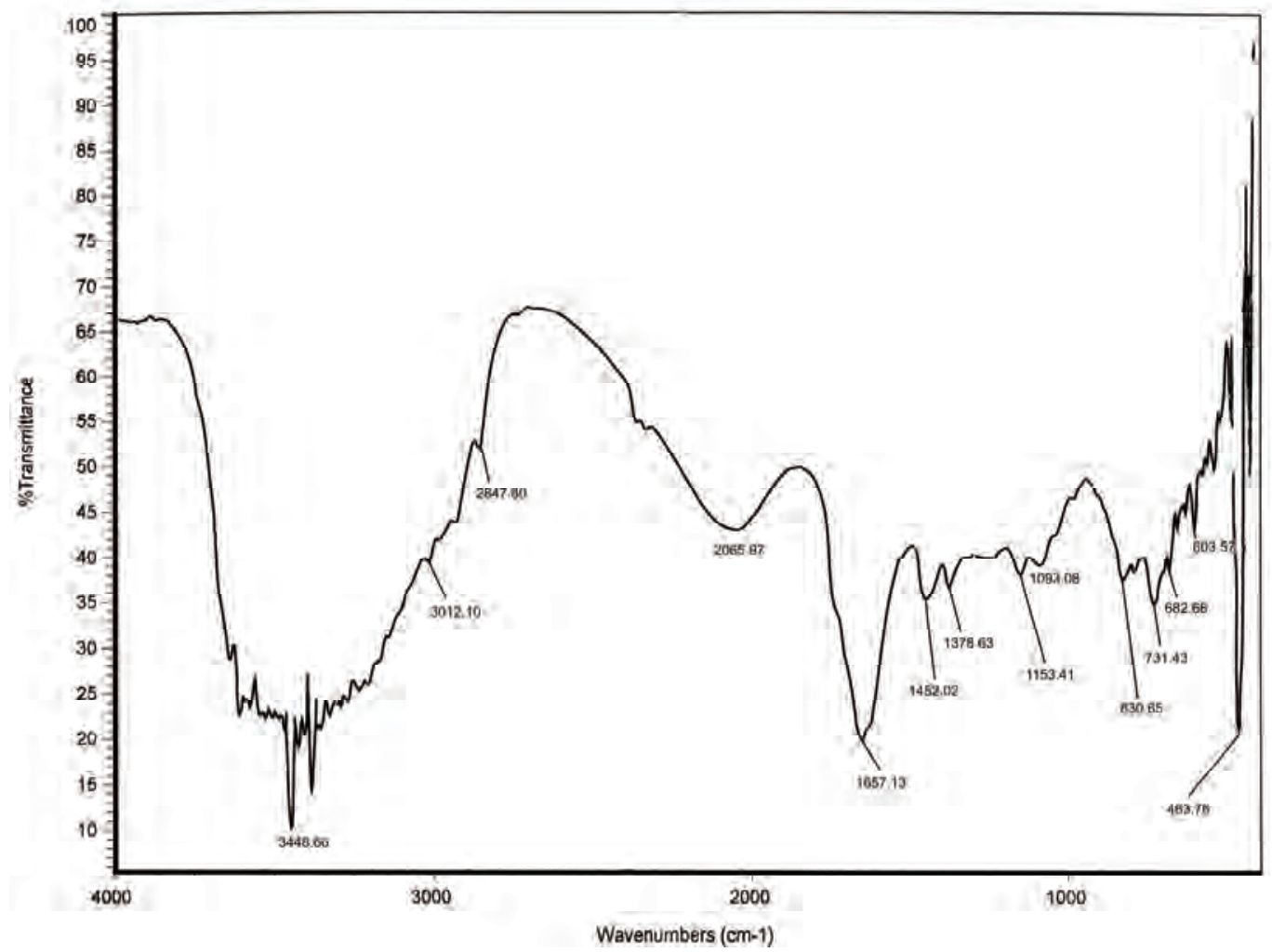

Figure 12. FTIR spectra of oxygenated emulsion.

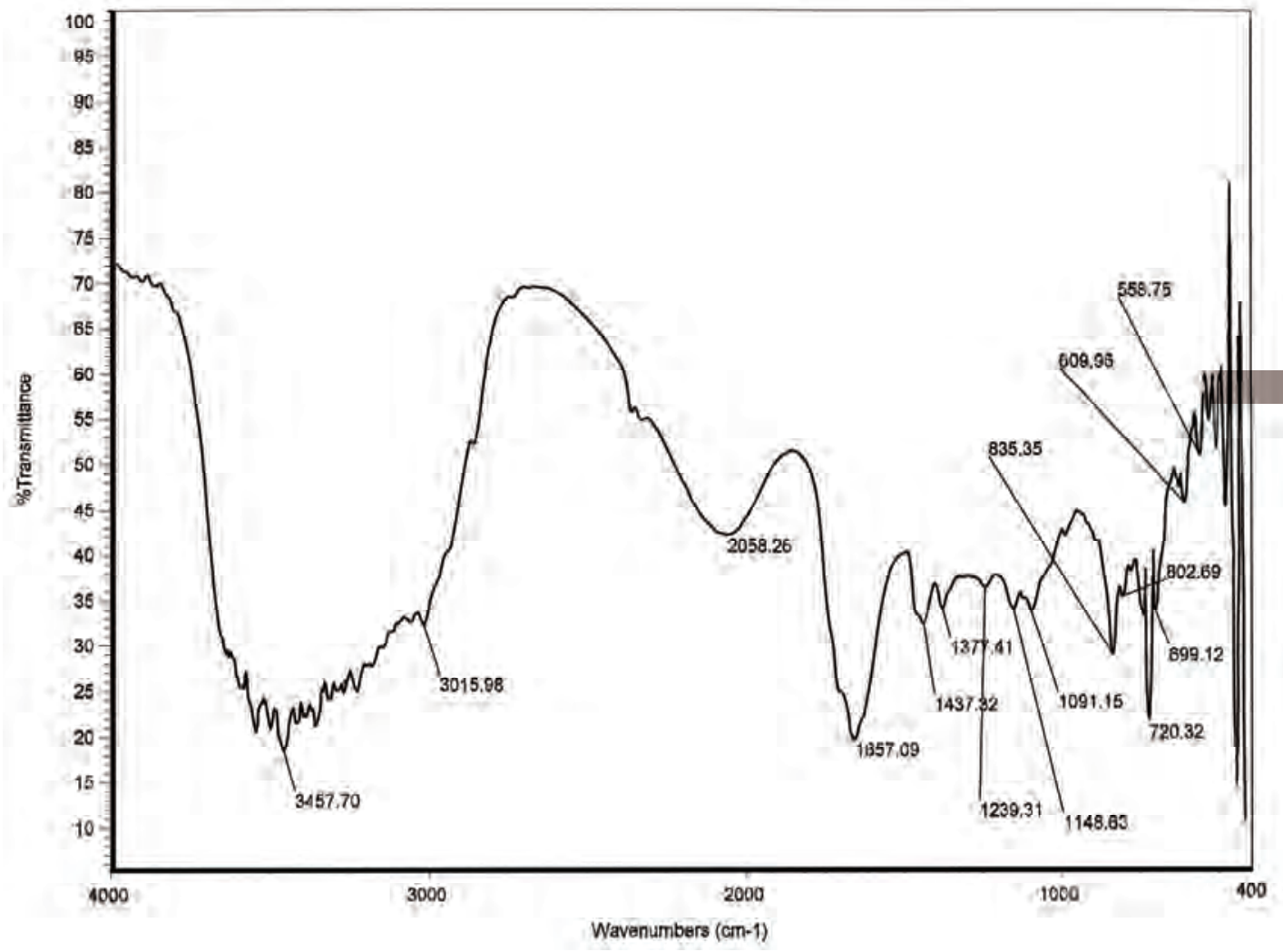

Figure 13. FTIR spectra of nitrogenated emulsion. 


\section{DISCUSSION}

In this study capability of gum odina as an emulsifying agent was investigated. Viscosity of the experimental emulsion was found to be $14 \mathrm{cP}$ which suggests that it was a thicker emulsion and the emulsion would remain stable for a longer period.

Dye test with Sudan III (oil soluble dye) showed that dye was distributed in the form of droplets throughout the colourless continuous phase. This proves that oil formed the dispersed phase and water was the continuous phase and it was an o/w type of emulsion. Thus o/w emulsion may be prepared using gum odina as emulsifying agent.

When the spectra were compared, in some cases peak height varied. It may be due to the presence of variable amounts of ingredients present in the pellet. There were interactions detected in the wave range numbers between $700 \mathrm{~cm}^{-1}$ and $600 \mathrm{~cm}^{-1}$. This zone is the known stretching vibration zone of $\mathrm{CH}$-alkane and $\mathrm{OH}$ ( $\mathrm{H}$ bonded and normally out of plane). Hydrogen of the fatty acid might have formed weak hydrogen bond or bond due to Van der Waal force or dipole moment with $\mathrm{OH}$ - group of water predominantly upon the long storage.

In the cases of thermal stability analysis, samples were kept at $20^{\circ} \mathrm{C}, 40^{\circ} \mathrm{C}$ and $60^{\circ} \mathrm{C}$ for 1 month (Figures 5-7) and compared with the freshly prepared sample (Figure 3). Changes in peaks in wave numbers between $2700 \mathrm{~cm}^{-1}$ and $720 \mathrm{~cm}^{-1}$ may be possibly due to interaction between ketonic and aldehyde groups in the fatty acids by formation of H-bonding or weak bondings such as Van der Waal forces or dipole moments, since the zone between $2690 \mathrm{~cm}^{-1}$ and $2840 \mathrm{~cm}^{-1}$ are the medium intensity and $1720 \mathrm{~cm}^{-1}-1740 \mathrm{~cm}^{-1}$ and $1710 \mathrm{~cm}^{-1}-1720 \mathrm{~cm}^{-1}$ are strong intensity carbomile stretching vibration zone and $720 \mathrm{~cm}^{-1}-725 \mathrm{~cm}^{-1}$ is the weak intensity bending vibration zone of $\mathrm{CH}_{2}$ rocking [30]. Reaction at the $1646 \mathrm{~cm}^{-1}$ and $718 \mathrm{~cm}^{-1}$ might be due to the opening of $\alpha$ and $\beta$ unstauration and interaction with $\mathrm{OH}$-group or $\mathrm{H}$ due to heating or $\mathrm{CH}_{2}$ rocking. Possible weak bond formation between $\mathrm{OH}$-group and carbonyl might have taken place at the wave range between $3200 \mathrm{~cm}^{-1}-3550 \mathrm{~cm}^{-1}$ as this zone is popularly known for variable and strong $\mathrm{OH}$ free and $\mathrm{OH}$ bonded stretching vibration zone.

Emulsion adjusted at different $\mathrm{pH}$ conditions (2, 7.4 and 10) and stored for 30 days were analyzed using FTIR spectroscopy and data were prepared with the freshly prepared emulsion ( $\mathrm{pH}-4.5)$. There were interactions between wave number $3500 \mathrm{~cm}^{-1}$ and $2600 \mathrm{~cm}^{-1}$ and at $1744 \mathrm{~cm}^{-1}$ at $\mathrm{pH}$ 7.4. The vibration at $3500 \mathrm{~cm}^{-1}$, $2600 \mathrm{~cm}^{-1}, 1744 \mathrm{~cm}^{-1}$ may be explained due to the weak bond formation of $\mathrm{OH}$ and carbonyl group present in water and fatty acid or between carbonyl or $\mathrm{CH}$ group of fatty acid and $\mathrm{OH}$ of water since these zones are the known stretching vibration zones of $\mathrm{OH}$ and $\mathrm{C}=\mathrm{O}$ group. By studying the FTIR spectra of the samples kept at different $\mathrm{pH}$ and the freshly prepared sample (Figures 8-10) it may be stated that emulsions at $\mathrm{pH} 7.4$ was more stable as compared to $\mathrm{pH} 2$ and $\mathrm{pH} 10$, considering the interaction patterns. Least interactions comparing to the freshly prepared and stable emulsion, was detected in case of emulsion with $\mathrm{pH}$ 7.4.

In case of photo-stability study, interactions might be due to the formation of weak bonds such as hydrogen bonds or bonds due to Van der Waal force or dipole moment between $\mathrm{OH}$ and $\mathrm{C}=\mathrm{O}$, since in the interaction zone predominant functional groups were $\mathrm{OH}$ and $\mathrm{C}=\mathrm{O}$. It suggests that the emulsion is photo-stable.

Peak variations at $2665 \mathrm{~cm}^{-1}$ and $3457 \mathrm{~cm}^{-1}$ of samples exposed to oxygen were probably due to the possible weak bond formation between $\mathrm{OH}$ and $\mathrm{COOH}$ of water and fatty acid respectively, since these are the known stretching vibration zones of $\mathrm{OH}$ and $\mathrm{C}=\mathrm{O}$ [30]. Peak variations at $1437 \mathrm{~cm}^{-1}$ and $1148 \mathrm{~cm}^{-1}$ could be due to $\alpha$ $\mathrm{CH}_{2}$ bending or C-C-C bending of fatty acid carbons, since, $1400 \mathrm{~cm}^{-1}-1450 \mathrm{~cm}^{-1}$ are the bending vibration zone of $\alpha-\mathrm{CH}_{2}$ and $1148 \mathrm{~cm}^{-1}$ is the medium intensity C-C bending vibration zone [30]. Thus, upon FTIR spectrum analysis, it may be stated that the emulsion is not susceptible to oxidation, since the reactions were due to physical bond formations. However, oxygenenation might have a role to induce such bond formations as they were not noticed in case of the samples exposed to $\mathrm{N}_{2}$.

Cracking may be caused by any chemical, physical or biological effect that changes the nature of the interfacial film that exists between oil and water [31]. These tend to make it less stable. But here, after long storage of prepared emulsion for 24 months, no coalescence of dispersed globules of oil was noticed. Hence, no cracking was observed in the said period.

Creams may be formed as a layer of relatively concentrated emulsion and this condition favors breakdown of the interface and consequent coalescence of the oil globules and therefore, the emulsion may eventually crack [31]. After a long storage of the emulsion for 24 months there were no cream formations on the upper surface of emulsion.

When experimental emulsions were compared with the prepared acacia emulsion (considered here as control), it was found that requirement of gum odina was $50 \%$ of the amount of acacia required for preparation of primary emulsion. Further, gum odina produces a stable emulsion which can be stored at least for 2 years.

Thus, gum odina may be used as an emulsifying agent to prepare $\mathrm{o} / \mathrm{w}$ primary emulsion.

\section{ACKNOWLEDGEMENTS}

The study was supported financially by Dr. V. Ravichandran Endowment Trust, Jadavpur University, Kolkata, India. 


\section{REFERENCES}

[1] Verbeken, D., Dierckx, S. and Dewettinck, K. (2003) Exudates gums: Occurrence, productions and applications. Applied Microbiology and Biotechnology, 63(1), 10-21.

[2] De Paula, R.C.M., Santana, S.A. and Rodrigues, J.F. (2001) Composition and rheological properties of Albizia lebbeck gum exudates. Carbohydrate Polymers, 44(2), 133-139.

[3] LeCerf, D., Irinei, F. and Muller, G. (1990) Solution properties of gum exudates from Sterculia urens (Karaya gum). Carbohydrate Polymers, 13(4), 375-386.

[4] Whistler, R.L. (1993) Exudate gums. In Whistler, R.L. and Berniller, J.N., Eds. Industrial Gums: Polysaccharides and their Derivatives. Academic Press, San Diego, 318-337.

[5] Philips, G.O. and Williams, P.A. (2001) Tree exudates gums: Natural and versatile food additives and ingredients. Food Ingredients Analysis of International, 23, 26-28.

[6] Cherukuri, S.R., Friello, D.R., Parker, E., Hopkins, W. and Mackay, D.A.M. (1983) Stable liquid red beet color and chewing gum containing same. U.S. patent 4, 371, 549.

[7] Huzinec, R.J. and Graff, A.H. (1987) Coatings for chewing gums containing gum arabic and a soluble calcium salt. U.S. patent 4, 681, 766.

[8] Eng, J.L. and Mackenzie, K.M. (1984) Glyceride fat based clouds for ready to drink beverages. US patent 4 , 479, 971.

[9] Ferdinand, G. and Kruger, W. (1986) Vitamin E effervescent tablets. German patent 3, 517, 916.

[10] Millard, R. and Balmert, C.A. (1961) Effervescent compositions. U.S. patent 2, 985, 562.

[11] Tame-said, J.I. (1997) Toothpaste and mouthwash in tablets. W.O. Patent 9, 719, 668.

[12] Weiping, W.T. and Karaya (2000) In Philips, G.O., Williams, P.A., Eds., Handbook of Hydrocolloids, Woodhead, Cambridge, 155-168.

[13] Dziezak, J.D. (1991) A focus on gums. Food Technology, 45(3), 116-132.

[14] Leupold, C.W., Kellner, W. and Hellmuth, J. (1962) Material with deodorizing action. G.B. patent 901, 554.

[15] Smith, G.R. and Wands, R.C. (1966) Compositions pro- viding a protective coating for the skin. G.B. patent 1 , 049, 063.

[16] Grossmith. F. (1956) Process for the production of jellies or viscous solutions. G.B. patent 750, 126.

[17] Nebergall, W.H. (1956) Dentrifice preparations. G.B. patent 746, 550.

[18] Partyka, A. (1963) Salad dressing. G.B. patent 936, 531.

[19] Steinhardt, A. and Goldwater, F.A. (1962) Gelatin adhesive pharmaceutical preparations. U.S. patent 3, 029, 187.

[20] Carpenters. (1979) Seals for colostomy or like bags. G.B. patent 2, 017, 501

[21] Marsan, A.E. (1967) Sealing pad for a post-surgical drainage pouch. U.S. patent 3, 302, 647.

[22] Sanderson, G.R. (1996) Gums and their use in food systems. Food Technology, 50(3), 81-84.

[23] Mukherjee, B., Samanta, A. and Dinda, S.C. (2006) Gum odina-a new tablet binder. Trends in Applied Sciences Research. 1(4), 309-316.

[24] Chidanbarathanu, S. (1995) Index of herbs in languages. Siddha Medical Literature Research centre, Madras.

[25] Kiritikar, K.R. and Basu, B.D. (1935) Indian Medicinal Plants, 2nd Edition, International Book Distributors, Book Sellers and Publishers, Dehradun.

[26] Kiritikar, K.R. and Basu, B.D. (1987) Indian Medicinal Plants, International Book Distributors, Book Sellers and Publishers, Dehradun.

[27] Carter S.J. (1987) Dispensing for Pharmaceutical Students, 12th Edition, CBS publishers and Distributors, Delhi.

[28] Grimm, W. (1998) Extension of the international conference on harmonization tripartite guideline for stability testing of new drug substances and products to countries of climatic zones III and IV. Drug Development and Industrial Pharmacy, 24(4), 313-325.

[29] Yoshiok, S., Ishihara, Y., Terazone, T. and Tsunakawa, N. (1994) Quinine actinometry as a method for calibrating ultraviolet radiation intensity in light-stability testing of pharmaceuticals. Drug Development and Industrial Pharmacy, 20(13), 2049-2062.

[30] Williams, G.P. (2002) Synchrotron and free electron laser sources of infrared radiation. Chalmers, J.M. and Griffiths, P.R., Eds., Handbook of Vibrational Spectroscopy, Wiley, Chichester, 341-342.

[31] Osol, A. (1980) Remington Pharmaceutical Sciences, Mack Publishing Company, Easton. 